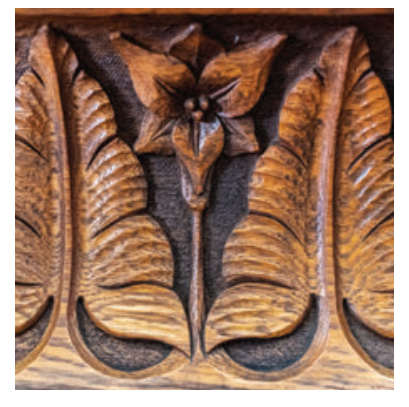

\title{
The People behind the Books
}

\section{Cornell University Press Staff}

\section{Director's Office}

Dean J. Smith, Director

Michael A. Morris, Assistant to the Director and Building Coordinator

\section{Acquisitions}

Mahinder Kingra, Editor in Chief

Emily Andrew, Senior Editor

Frances Benson, Editorial Director, ILR Press

Sarah E. M. Grossman, Managing Editor, SEAP Publications

Roger Haydon, Executive Editor

James Lance, Senior Editor

Kitty Liu, Editor, Comstock Publishing Associates

Michael J. McGandy, Senior Editor and Editorial Director, Three Hills

Bethany Wasik, Assistant Editor

Meagan Dermody, Acquisitions Assistant

Ellen F. Murphy, Acquisitions Assistant

\section{Subsidiary Rights and Permissions}

Tonya Cook, Subsidiary Rights Manager

Stephanie Munson, Permissions Coordinator 


\section{Manuscript Editing}

Ange Romeo-Hall, Managing Editor

Sara Ferguson, Production Editor

Karen Hwa, Senior Production Editor

Jennifer Savran Kelly, Production Editor

Karen M. Laun, Senior Production Editor and Digital Publishing Editor

Susan Specter, Senior Production Editor

James McCaffery, Digital Publishing Assistant

\section{Design and Production}

Scott Levine, Art Director

Richanna Patrick, Designer and Apple IT

Diana R. Silva, Senior Production Coordinator

Bill Oates, Production Coordinator

\section{Marketing and Sales}

Martyn Beeny, Marketing and Sales Director

Adriana M. Ferreira, Social Media Coordinator

Nathan D. Gemignani, Special Sales Representative and Metadata

Carmen Torrado Gonzalez, Marketing Assistant

Jonathan L. Hall, Digital Marketing Manager

David Mitchell, Exhibits, Advertising, and Awards Coordinator

Cheryl Quimba, Publicity Manager

\section{Business Office}

Lynn A. Benedetto, Finance and Royalty Manager

William O’Dell Wehling, Accounts Representative

Kate Leboff, Project Manager

\section{Information Technology}

Patrick Garrison, CIS Computing Manager and IT Administrator 


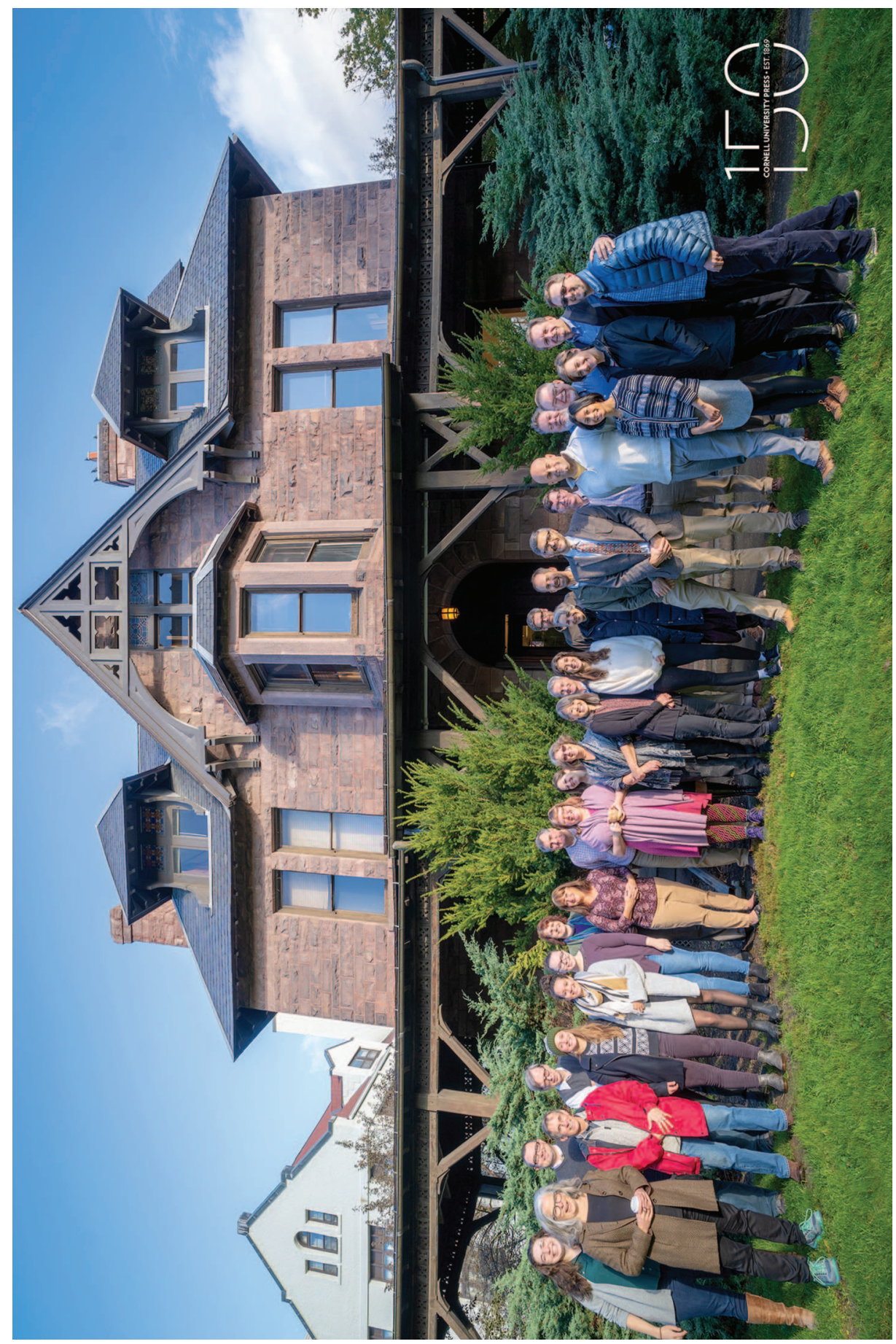

